\title{
Nurse triage in theory and in practice
}

\author{
S. GEORGE, S. READ, L. WESTLAKE, B. WILLIAMS, \\ P. PRITTY \& A. FRASER-MOODIE \\ Medical Care Research Unit, Department of Public Health Medicine, University of \\ Sheffield Medical School, Beech Hill Road, Sheffield S10 2RX and Derbyshire Royal \\ Infirmary, London Road, Derby DE1 2QY
}

\section{SUMMARY}

'Nurse Triage' refers to the formal process of early assessment of patients attending an accident and emergency (A\&E) department by a trained nurse, to ensure that they receive appropriate attention, in a suitable location, with the requisite degres of urgency. The benefits claimed for nurse triage include better patient outcomes through clinical management reaching those in greatest need of it first.

A recent study of nurse triage in a British A\&E department failed to demonstra the benefits claimed: patients undergoing triage were delayed, especially those the most urgent groups. No differences were noted between the two study groups in levels of satisfaction with the A\&E process.

The results brought forth criticism from all quarters. In this paper the points $\frac{D}{\Phi}$ made by the critics are considered, and an attempt to answer them is made.

\section{INTRODUCTION}

In the field of A\&E care, persistently rising attendances (Milner et al., 1988), problems of inappropriate use, long waiting times, overcrowding and aggression are all familiar stories, that have invited solutions. One strategy that has gained wide acceptance, first in the U.S.A. and then in the U.K., is the introduction of nurse triage.

'Nurse triage' refers to the formal process of early assessment by a trained nurse, in an attempt to ensure that patients receive appropriate attention, in a suitable location and with the requisite degree of urgency (Rund \& Rausch, 1981; Estrada, 1981). This has often occurred informally in the past, usually by reception

Correspondence: Steve George, Senior Lecturer in Public Health Medicine, University of Southampton, Wessex Institute of Public Health, Level B, South Academic Block, Southampton General Hospital, Tremona: Road, Southamiton SO9 4XY. 
staff, in line with other moves to extend the nursing role trained nurses practise formal 'triage' with increasing frequency, with much attention paid to the documentation of patients seeing the triage nurse. Systems for deciding degrees of urgency may be based upon explicit criteria (e.g. listing specific sites of injury, symptoms and signs), or may be more normative in character (e.g. assigning patients to priority groups, according to the maximum time that it is estimated they should wait to be treated, or merely placing them in rank order).

The benefits claimed for triage are twofold: firstly, an overall reduction in waiting time for A\&E attenders, (Beach, 1981; Shields, 1976; Slater, 1970; Nuttall, 1986; Bailey et al., 1987; Grose, 1988; Maidens, 1988; Mallet \& Woolwich, 1990) particularly for those in need of the most urgent attention; secondly, a reduction in levels of anxiety in patients, or in those accompanying them, as they are reassured from the outset either that their condition requires and will receive prompt attention, or that the situation is under control clinically and that the ensuing delay, while inconvenient, will not be harmful, (Wright, 1985; McMillan, et al., 1986)

However, much of the research into the benefits of triage has been either small scale and anecdotal (Beach, 1981; Shields, 1976; Slater, 1970; Nuttall, 1986; Grose, 1988; Maidens, 1988; Wright, 1985) or has suffered from methodological weaknesses (Bailey et al., 1987; Mallet \& Woolwich, 1990). In 1990 we performed a study designed to rectify these deficiencies (George et al., 1992a).

\section{Brief description of the 1990 study}

The study was preceded by a long and complex pilot study, during which much attention was paid to the removal of biases from the design (Read et al. 1992).

A 6-week study time was divided into six 7-day periods and then allocated alternately as triage and no-triage weeks. Lack of a triage nurse on 6 half-day shifts within weeks allocated to triage necessitated their re-designation as notriage shifts. Triage was then run on the corresponding half-day shifts of the following no-triage weeks, ensuring that an equal number of comparable halfdays were allocated to each study group. A total of 5954 new patients were recruited attending between 8.00 a.m. and 9.00 p.m. at our study site, excluding those attending by appointment (e.g. to fracture clinics) or by prior arrangement for admission as in-patients. Patients were grouped for analysis on an intention to treat' basis, according to the regime operating during the half-day shift in which they presented. During triage weeks a trained 'triage nurse' assessed patients upon arrival, and formally assigned them to one of four treatment categories according to urgency, before they proceeded to reception. During no-triage weeks a combination of nursing staff assessed patients informally following booking in at reception.

The degree of urgency of each patient was assessed retrospectively from the clinical record by either one of two consultant A\&E clinicians, who were 'blinded' as to whether an individual patient had undergone triage or not. They placed patients into one of four priority categories (One $=$ most urgent; four $=$ least urgent). These categories were used as a 'Gold Standard' for the purposes of analysis, to ensure case-mix comparability between the two study groups. 
For each patient attending, the time between first attendance in the department and obtaining medical attention was measured. Complete waiting time data were obtained on 5037 patients (85\%). Median waiting times between the study groups for patients in each priority category were compared, calculating the significance of the difference in each case using a Mann-Whitney U-Test, and confidence intervals for the difference by the method described by Nicholl (1989). A sample of $\frac{\sigma}{\omega}$ patients received a piloted patient satisfaction questionnaire containing fourteen items relating to the patient's opinion of the time waited in the department, inconvenience suffered, anxiety experienced, and the level of information received during the visit. Differences in responses between the two groups were assessed using Chi-square tests.

The results showed that the intention to triage did not produce all the benefits claimed. Formal nurse triage significantly delayed those patients in most urgent $\stackrel{3}{3}$ need of care, and little difference was found in patient satisfaction. Further analy- $\vec{\circ}$ sis (George et al. 1992b) implicated queuing problems caused by triage nurses ${ }_{i}^{\omega}$ prioritizing patients higher than was strictly necessary as the cause of delay.

These results, when published and presented, produced an immediate and often 은 incensed reaction (Cruickshank, 1992; Dale, 1992; Bache, 1992; Heyworth \& Pledge, $\vec{c}$ 1992; Porter, 1992; St George, 1992). In this paper an attempt is made to explore in $\mathbb{D}$ depth some of the points raised by these critics.

\section{Criticisms of the 1990 study}

It is possible to summarize the criticisms made of the study under several heading and an attempt is made to answer them in turn. However, no attempt will be made to answer the occasionally heard 'You must have fiddled the figures', or 'You must have something against nurses as a profession' except to say that the authors are guilty of neither.

(1) 'Only $48 \%$ of your patients attending designated triage sessions saw a triage $\overrightarrow{\overrightarrow{0}}$ nurse, although you intended all of them to do so. This invalidates your results'. This is $\exists$ not a failing of the study, but is a result. The study asked the question 'does triage, in a real life situation, produce the benefits claimed for it?'. This is the question actually faced by clinicians, and is of considerable importance. It is therefore of interest to know that despite all efforts to keep triage running during the study periods more than half the patients 'slipped through the net'. Only 1213 $(48 \%)$ of those 2515 patients who attended during a period designated for triage actually received a triage categorization decision. The reasons for this finding are worth examining. It is not thought that this was due to missing triage assessment forms: one of the functions of the pilot study was to investigate record completeness, and $95 \%$ of triage assessment forms were retrieved (Read et al. 1992). It is believed that this is due to a combination of factors: triage nurses must stop for refreshments, and covering staff are often unavailable. Although the study attempted to counter the effects of staff shortages, by ensuring that triage was running at the beginning of each half-day period assigned to it, it is possible that at busy times, paradoxically, triage was sacrificed to free nurses for clinical duties. Also, when pressure on a $\frac{\mathbb{D}}{\mathbb{2}}$ department builds up, it is possible that some patients bypass the triage station and, despite their ostensible inclusion within the scheme, some extremely urgent patients might also bypass the triage nurse. 
In order to satisfy curiosity the data have been re-analysed and an analysis of waiting times and patient satisfaction items according to whether each patient was actually seen by a triage nurse or not is presented here, based upon the evidence of a written triage record. This attempts therefore to answer a different question from that posed above: 'Would triage, in an ideal situation, produce the benefits claimed for it?'. The reader must be warned against placing too much faith in these results, however, since there will certainly be an element of selection bias. Table 1 shows that median waiting times were shorter in the group not seen by a triage nurse in priority categories one and two (the most urgent categories), and longer in priority categories three and four, than in the group seen by a triage nurse, although this difference is only significant in priority category one $(P=0.02$; $95 \%$ CI for difference $4-31.5 \mathrm{~min}$ ). Table 2 shows that no items on the patient satisfaction questionnaire were answered significantly differently by patients in the two study groups. These results are similar to those in the earlier study, and the fact that only $48 \%$ of our study population saw a triage nurse, therefore, has little bearing.

(2) 'The time periods during which you ran and did not run triage were obviously different. You did not compare like with like.' The method of allocation of time periods in the study is described above. The re-allocation of a half-day shift happened in only 6 of the 42 half-days allocated to triage, and the decisions to redesignate shifts were made at the beginning of each day, not at a moment's notice, nor in response to suddenly increased workload during a shift. It was ensured that triage ran on each session designated. The time periods in which nurse triage ran, and did not run, were therefore entirely comparable, and were not dictated by workload.

(3) 'Your study was carried out in only one site, and the results cannot be extrapolated to all sites'. This statement is in part true. The study was carried out at only one site, a department in a major district general hospital with more than 60000 new attendances annually and with 5 years of triage experience. However, the site was chosen because it was typical of many others, and whether the results apply to other departments or not is yet to be determined. A search of the literature reveals few studies which attempt to evaluate differences made to waiting times by the

Table 1. Median waiting time (minutes) by whether seen by triage nurse and by retrospective priority category

\begin{tabular}{lccccc}
\hline & \multicolumn{3}{c}{ Median waiting time (min) } & & \\
\cline { 2 - 5 } $\begin{array}{l}\text { Retrospective } \\
\text { priority } \\
\text { category }\end{array}$ & $\begin{array}{c}\text { Seen by } \\
\text { triage } \\
\text { nurse } \\
(\mathrm{n}=1213)\end{array}$ & $\begin{array}{c}\text { Not seen } \\
\text { by triage } \\
\text { nurse } \\
(\mathrm{n}=3824)\end{array}$ & $\begin{array}{c}\text { Difference } \\
\text { (seen } \\
\text { minus } \\
\text { not seen) }\end{array}$ & $\begin{array}{c}\text { Significance } \\
\text { (Mann-Whitney) }\end{array}$ & $\begin{array}{c}95 \% \\
\text { Confidence } \\
\text { intervals } \\
\text { for difference } \\
\text { (Nicholl) }\end{array}$ \\
\hline $\begin{array}{l}\text { One } \\
\text { (most urgent) }\end{array}$ & 30.5 & 18 & 12.5 & $P=0.02$ & +4 to +31.5 \\
$\begin{array}{l}\text { Two } \\
\text { Three }\end{array}$ & 44.0 & 41 & 3.0 & $P=0.25$ & -3 to +9 \\
$\begin{array}{l}\text { Four } \\
\text { (least urgent) }\end{array}$ & 56.5 & 57 & -0.5 & $P=0.62$ & -5 to +6 \\
\hline
\end{tabular}


Table 2. Responses to Patient Satisfaction Questionnaire containing 14 items related to patients' opinions of time waited, inconvenience suffered, anxiety experienced and level of information received during the $A \& E$ visit

\begin{tabular}{|c|c|c|c|c|c|}
\hline & \multicolumn{2}{|c|}{$\begin{array}{l}\text { Seen by } \\
\text { triage nurse } \\
(n=181)\end{array}$} & \multicolumn{2}{|c|}{$\begin{array}{l}\text { Not seen by } \\
\text { triage nurse } \\
\quad(n=526)\end{array}$} & \multirow{2}{*}{$\begin{array}{c}\text { Significance } \\
\text { of difference } \\
\left(\chi^{2}\right)\end{array}$} \\
\hline & No. & $\%$ & No. & $\%$ & \\
\hline \multicolumn{6}{|l|}{ Time waited to book in was: } \\
\hline about right & 67 & 37 & 242 & 46 & $P=0.07$ \\
\hline longer than expected & 31 & 17 & 60 & 11 & \\
\hline much too long & 7 & 4 & 26 & 5 & \\
\hline total responses & 180 & 100 & 520 & 100 & \\
\hline missing responses & 1 & & 6 & & \\
\hline \multicolumn{6}{|l|}{ Time waited to see doctor was: } \\
\hline shorter than expected & 41 & 23 & 105 & 20 & \\
\hline about right & 56 & 31 & 153 & 29 & $P=0.08$ \\
\hline longer than expected & 52 & 29 & 127 & 24 & \\
\hline much too long & 31 & 17 & 137 & 26 & \\
\hline total responses & 180 & 100 & 522 & 100 & \\
\hline missing responses & 1 & & 4 & & \\
\hline \multicolumn{6}{|c|}{ Inconvenience was suffered due to: } \\
\hline absence from work & $32 / 154$ & 21 & $102 / 440$ & 23 & $P=0.62$ \\
\hline absence from home & $54 / 161$ & 34 & $184 / 474$ & 39 & $P=0.27$ g \\
\hline missing social engagement & $13 / 141$ & 9 & $45 / 425$ & 11 & $P=0.76 \Omega$ \\
\hline \multicolumn{6}{|l|}{ Anxiety was experienced due to: } \\
\hline absence from work & $27 / 148$ & 18 & 78/411 & 19 & $P=0.94 \lesseqgtr$ \\
\hline absence from home & $47 / 155$ & 30 & $154 / 443$ & 35 & $P=0.36 \stackrel{0}{2}$ \\
\hline missing social engagement & $10 / 145$ & 7 & $33 / 406$ & 8 & $P=0.76^{\circ}$ \\
\hline nature of illness or injury & $84 / 156$ & 54 & $281 / 449$ & 63 & $P=0.07$ \\
\hline pain due to illness or injury & $75 / 155$ & 48 & $248 / 442$ & 56 & $P=0.12$ \\
\hline long-term effects of illness & $56 / 152$ & 37 & $183 / 427$ & 43 & $P=0.23$ \\
\hline \multicolumn{6}{|l|}{ Information was received about: } \\
\hline probable waiting time & $65 / 171$ & 38 & $151 / 485$ & 31 & $P=0.12$ \\
\hline nature of treatment & $57 / 166$ & 34 & $167 / 490$ & 34 & $P=1.00$ \\
\hline nature of illness or injury & $54 / 168$ & 32 & $146 / 486$ & 30 & $P=0.68$ \\
\hline
\end{tabular}

presence of a triage system, and finds even fewer with any scientific validity. In 8 the absence of any convincing evidence to the contrary, then, these results are the $₹$ best available. It is interesting to note, also, that similar results have been obtained 9 elsewhere. A recent British study found that the introduction of triage resulted in $\frac{7}{2}$ a statistically significant increase in the time waited to see a doctor (Mallet \& Woolwich, 1990). A 1976 American study showed that time savings brought about $\stackrel{\sim}{\circ}$ by triage were among those patients with less urgent conditions, and that no $\tilde{O}$ difference was made to the time waited by patients needing more urgent attention $\underset{\omega}{\widetilde{N}}$ (Shields, 1976). Surprisingly, the authors of both of these studies continued to voice their support for nurse triage.

(4) 'This is not an evaluation, but an audit, and it cannot be applied to all departments'. Whether the study is audit or evaluation is a semantic argument: however, some 
would claim that audit is evaluation against agreed standards. Since there are (or were) no agreed standards for nurse triage, but only claimed benefits, the study is an evaluation. It does, however, provide a methodological basis for others to audit their departments.

(5) 'Your assessment of urgency should have been made by nurses, rather than doctors, and should have been prospective, rather than retrospective.' In answer to the first part of this point, so long as all groups in a study such as this are judged by the same assessors, the assessors could be nurses, doctors or trained research workers. The choice of doctors rather than nurses was based upon a part of the pilot study, which demonstrated lower inter-observer variation amongst the doctors than the nurses at the study site. In answer to the second part, it would be ethically unacceptable to use prospective categories for this purpose, as it would entail giving every patient a triage decision, and then ignoring the decision in half the cases. Therefore, retrospective assessment was the only choice.

(6) 'Since all the nurses at your study site were trained in triage, there was contamination between the two study groups.' This is undoubtedly true. However, there can scarcely be an A\&E nurse in the country who has not heard of triage, and who does not appreciate its objectives. The authors stress again that a formal triage process, involving a documented assessment governed by strict protocols, was being tested against an informal assessment process proceeding in an undocumented, intuitive and dynamic manner. It was never the aim, and it would have been an unrealistic exercise, to compare a triage system against a system where patients were seen in strict order of arrival. Study designs which would eliminate any chance of contamination bring with them their own problems: a 'before and after' design, for instance, is difficult to interpret in the light of underlying secular trends, and a study comparing two departments, one with triage and one without, must be controlled for any and all other differences which might exist between the two departments.

(7) 'There is something wrong with your training of triage nurses, or they lack experience.' Triage ran for 5 years preceding the study. All triage nurses attend six lectures, are tested on theory, and undertake supervised practice, before starting triage. Their collective skills and experience are as good as those at any site in the country.

(8) 'You have used the wrong outcome measures - you should have measured real patient outcomes instead of a proxy like waiting time.' Two things were measured in the study. One, patients' satisfaction with the A\&E process, is an outcome, and no differences were noted between those attending when triage was operating and those when it was not. The other measure, time waited before seeing a doctor, is indeed a proxy measure. It is likely that our critics refer. specifically to outcomes such as lives saved, or deaths avoided. It should be realized, however, that the measurement of these outcomes, whilst easy in cases of serious trauma and in medical cases where there is severe physiological disturbance, is difficult in cases of minor trauma or minor medical ailment, or indeed in patients with nothing wrong with them. The variety of case presentations in an A\&E department, and the multideterminate nature of the outcome of each case, make the attribution of these sorts of outcomes to the pattern of care extremely difficult. It is likely that the extension of waiting time would have made a difference in terms of lives saved or 
deaths avoided in only the most urgent of the four categories of patients, as $\stackrel{\oplus}{\oplus}$ classified by the two doctor assessors. This category formed only 179 of 50373 patients in the study $(3.6 \%)$, and it is by no means certain that all of these cases? would have had a different outcome brought about by an alteration in the waiting $\underset{\vec{c}}{\overrightarrow{0}}$ time. In order to conduct a study using these measures which would enable a comparison between two systems of treatment, therefore, the population of patients studied would have to be very much larger than that in our study. It was for this $\frac{\vec{\omega}}{\vec{\sigma}}$ reason that a proxy outcome was chosen, i.e. the time taken to receive medical $\stackrel{\Phi}{\circ}$ care, on the assumption that a shorter waiting time would, in general, lead to a more beneficial outcome. This proxy measure was chosen after careful study of $\vec{\circ}$ the relevant literature. Since the publication of the study, however, the measure $\overrightarrow{\vec{\omega}}$ has been criticized. It has been suggested that a better measure would be time $\stackrel{\omega}{\circ}$ taken to receive first clinical rather than medical care (i.e. from a nurse, doctor $\stackrel{\oplus}{3}$. or other professional). This was not measured, but there is nothing to suggest that care was obtained differently in the two arms of the study. In trying to define $w$ 'first clinical intervention' it is important to realize that intervention must be distinguished from assessment alone. Assessment will produce no benefit unless ${ }_{\circ}^{\circ}$ it leads to a subsequent alteration in practice. This points to the need for a large $\stackrel{\Xi}{-}$ scale study of the processes which take place within A\&E departments, in order $\Phi$ that 'first clinical intervention' can be more clearly defined, and reliable observations $\frac{\mathbb{O}}{\mathbb{D}}$ made of it.

\section{DISCUSSION}

It is not easy to imagine a mechanism by which waiting times could be reduced overall by the presence of a nurse triage system. The only way in which this could occur would be for nurse triage in some way to increase the overall efficiency of $\stackrel{\circ}{\rightarrow}$ the A\&E process. Rather, one might expect a redistribution of waiting times, with $\overrightarrow{\overrightarrow{0}}$ the most urgent patients receiving attention most quickly, at the expense of those less in need of attention. Although the study demonstrated a redistribution of waiting times, it was, unfortunately, in the opposite direction to that desired.

It is easier to suggest a putative causative mechanism for a reduction in anxiety $\stackrel{3}{*}$. or for an increase in patient satisfaction, given that patients might have received early attention from a member of staff. Nevertheless, the study found no such differences.

This gap between theory and practice demonstrates the need for regular audit, 9 and the danger in assuming that a system functions as intended. The introduction? of triage in the study department led to a queuing problem, which ultimately, led to delays for all patients. It is important, when departments are reviewing theiro own triage arrangements, to be aware of the problems caused by 'over-triaging': N not all patients can go to the front of the queue.

Despite the lack of convincing evidence for its beneficial effect, it is clear that there is widespread support for nurse triage. Half of the A\&E departments ince England and Wales practice some form of triage (Department of Health, 1989; Pledge \& Rock 1988), and in line with the recommendations of the Patient's 
Charter (Department of Health, 1991), the British Association of Emergency Medicine (BAEM, 1992), and the National Audit Office (1992) this proportion is likely to increase. Why is this? Subjectively, it has been found that nursing staff are more confident when triage is in operation. This may represent a reduction in anxiety, brought about by the knowledge that all patients in the waiting room have been assessed by a health professional, and that they should suffer no unexpected mishaps. Alternatively, the stress imposed by working in a demand-led system may be reduced by giving those who work within it an element of control over the demand.

It is not enough to assume that a good theory translates automatically into practice. Each A\&E department must audit whether nurse triage as currently practised is fulfilling its objectives. Much criticism of the study has been made by individuals and departments committed to nurse triage. However, the authors believe that it is the best study of the subject performed so far. It is for others to justify their faith in an unproven and expensive intervention, rather than for the authors to justify their scepticism.

\section{ACKNOWLEDGEMENTS}

The authors are grateful to the medical, nursing and administrative staff of Derbyshire Royal Infirmary, and particularly to Janice Glasgow and Tony Potter, for their enthusiastic cooperation and tolerance; to Lesley Thorpe, research coordinator, for her painstaking work in data collection; and to Dr Gillian Spencer and Dr Simon Voss for their comments on the manuscript.

The work was funded by the Department of Health, which, with Trent Regional Health Authority, maintains the Medical Care Research Unit. The authors would like to thank them for their support. The views expressed in this paper are those of the authors alone.

\section{REFERENCES}

Bache J. (1992) Nurse triage in accident and emergency departments, British Medical Journal 304, 1378. Bailey A., Hallam K. \& Hurst K. (1987) Triage on trial. Nursing Times 83, 65-66.

Beach L. (1981) Paediatric emergency services triage. Journal of Entergency Nursing 7(2), 50-55.

British Association of Emergency Medicine (1992), The Way Ahead (Draft Report).

Cruickshank R. (1992) Nurse triage in accident and emergency departments. British Medical Journal 304, 1378.

Dale J. (1992) Nurse triage in accident and emergency departments, British Medical Journal 304, 1378.

Department of Health (1989) Nurse triage and use of nurse practitioners in AEE departments in a Survey via $R N O s$. Unpublished internal report, London.

Department of Health (1991) The Patient's Charter. HMSO, London.

Estrada E. (1981) Triage systems. Nursing Clinics of North America 16(1), 13-24.

George S. L., Read S., Westlake L., Williams B. T., Fraser-Moodie A. \& Pritty P. (1992a) Evaluation of nurse triage in a British accident and emergency department. British Medical Journal 304, 876-878.

George S. L., Westlake L., Read S., Williams B. T., Fraser-Moodie A. \& Pritty P. (1992b) Nurse triage in 
accident and emergency departments (Authors' reply). British Medical Journal 304, 1379.

Grose A. (1988) Triage in accident and emergency. The Professional Nurse 3(10), 400-402.

Heyworth J. \& Pledge M. (1992) Nurse triage in accident and emergency departments. British Medical

Journal 304, 1378.
McMillan J. R., Younger M. S. \& DeWine L. C. (1986) Satisfaction with hospital emergency department as function of patient triage. Health Care Management Review 11(3), 21-27.

Maidens S. (1988) East Survey Triage Success. Nursing Standard 2(6), 18.

Mallet J. \& Woolwich C. (1990) Triage in accident and emergency departments. Journal of Advanced Nursing 15, 1443-1451.

Milner P. C., Nicholl J. P. \& Williams B. T. (1988) Variation in demand for A\&E departments in England and Wales 1975-85. Journal of Epidemiology and Comminity Health 42(3), 274-278.

National Audit Office (1992) NHS A\&E Departments in England. HMSO, London.

Nicholl J. P. (1989) Conceptual and technical considerations about using medians to evaluate the outcome of pragmatic clinical trials. Given at International Society of Clinical Biostatistics - 10, Maastricht, September 1989, revised October 1989.

Nuttall M. (1986) The chaos controller Nursing Times 82, 66-68.

Pledge M. N. \& Rock D. (1988) Priorities of care for the walking wounded, Report for Queen Alexandra. Hospital, and S. E. Hants Health Authority, Portsmouth.

Porter J. (1992) Nurse triage in accident and emergency departments, British Medical Journal 304, 1378-1379.

Read S., George S., Westlake L., Williams B., Glasgow J. \& Potter T. (1992) Piloting an evaluation of triage. International Journal of Nursing Studies 29(3), 275-288.

Rund D. A. \& Rausch T. S. (1981) Triage. Mosby, St Louis.

Russo R. M., Gururaj V. J., Bunye A. S., Kim Y. H. \& Ner S. (1975) Triage abilities of nurse practitioner vs paediatrician. American Journal of Diseases in Children 129, 673-675.

Shields J. E. (1976) Making triage work: the experience of an urban emergency department. Journal of Emergency Nursing 2(4), 37-41.

Slater R. (1970) Triage nurse in the emergency department. American Journal of Nursing 70(1), 127-128

St George D. (1992) Nurse triage in accident and emergency departments. British Medical Journt 304, 1379.

Wright R. (1985) Hostility in accident and emergency departments. Nursing Mirror 161(14), 42-44. 